\title{
Syngas from Updraft Gasifier Incineration for Internal Combustion Engine Power Generation in Klongluang PathumThani Thailand
}

\author{
Krissadang Sookramoon \\ Faculty of Industrial Technology Vallaya Alongkorn Rajabhat University 1 Moo 20 TambolKlongnueng Amphoe Klongluang PathumThani, \\ Thailand
}

\begin{abstract}
This paper presents the internal combustion engine power generation using syngas from the updraft biomass gasifier as a fuel. 3 types of fuel such as Golden shower tree wood chip, charcoal, and gasohol 91 were tested for the engine running. The experiment was performed on July 25-26, 2017 at Faculty of Industrial Technology Vallaya Alongkorn Rajabhat University Pathum Tani Thailand. Data on the performance of the engines fueled with producer gas and gasohol 91 is presented. The experiment was carried out by using a four-stroke 13 HP gasoline engine coupled with a generator as a load in producing electricity. The carburetor was modified for fuel gas running by loading $7 \mathrm{~kg} /$ batch of Golden shower chips and charcoal for syngas producing and the engine performance was measured. The results showed that, the engine power was $110.125 \mathrm{~W}, 115.425 \mathrm{~W}$, and $128.038 \mathrm{~W}$, while using a golden shower chip, charcoal, and gasohol 91 as the fuel, respectively. The generator efficiency is $80 \%$ therefore the generator power reduces $20 \%$. The test indicated that golden shower chips could produce higher quality of syngas than charcoal but the engine power has less power than fueled with gasohol 91.
\end{abstract}

\section{Introduction}

The use of biomass energy as a renewable energy such as charcoal, rice husk or in the form of scrap, which are locally available resource. The syngas is composed of carbon monoxide $(\mathrm{CO})$, hydrogen $\left(\mathrm{H}_{2}\right)$ and methane $\left(\mathrm{CH}_{4}\right)$, which can be used as fuel instead of petroleum fuel oil in the internal combustion engine. Although biomass gasification is considered as an ancient technology, the consequence of the use of this technology has increased in order to preserve fossil fuel resources and decrease greenhouse gas productions. The removing of tar from producer gas has been found to be a major problem for engine applications. It can be used as fuel instead of petroleum fuel in internal combustion engine such as gasoline engines both large and small. The performance test of a gasifier used for this small engine can be used as a machine in place to generate electricity, pumping water, etc., driving the machines in the agricultural sector.

Golden shower tree, in other word Cassia fistula is a fast-growing, medium-sized, deciduous tree which is now widely cultivated in Thailand as an ornamental tree for its attractive dramatic yellow flowers. Synthesis gas (syngas), a gas mixture that contains varying amounts of carbon monoxide $(\mathrm{CO})$ and hydrogen $\left(\mathrm{H}_{2}\right)$ generated by the gasification of a carbon containing material to a gaseous product with a heating value (but less than half the energy density of natural gas). When used as a fuel, it is formed by gasification of coal or municipal waste by the subsequent reactions: $\mathrm{C}+\mathrm{O}_{2} \rightarrow \mathrm{CO}_{2} ; \mathrm{CO}_{2}+\mathrm{C} \rightarrow$ $2 \mathrm{CO} ; \mathrm{C}+\mathrm{H}_{2} \mathrm{O} \rightarrow \mathrm{CO}+\mathrm{H}_{2}$. The name comes from the gas's use as an intermediate in generating synthetic natural gas (SNG) and in generating ammonia or methanol. Biomass updraft gasifier, coupled with reciprocating internal combustion engines is an applied technology for minor scale power generations.

\section{Updraft gasification systems}

The updraft gasifier is the simplest and oldest form of the fixed bed gasifier. Syngas flow countercurrent to each other. The responsive agent is injected at the bottom of the reactor and ascends to the upper while the fuel is introduced at the top and descends to the bottom through zones of gradually increasing temperatures (drying, pyrolysis, gasification and oxidation). Heat from the gasification and oxidation zones rises upward to deliver energy for the pyrolysis and drying zones. Gases, tar and other volatile compounds are dispersed at the top of the reactor while ash is removed at the bottom. The syngas normally contains high levels of tar, which must be removed or further converted to syngas for use in applications other than direct heating. The producer gas exits at low temperature $\left(80-300{ }^{\circ} \mathrm{C}\right)$ and contains an abundance of oils and tar (10-20\%) since the products of the pyrolysis and drying zone are directly drawn into it without decomposition. The dust content in the producer gas is low due to low gas velocities and filtering effect of feed in drying and pyrolysis zones [1-4]. Yang, et al., 
(2006) investigated high temperature agent gasification (HiTAG) of wood pellets in a batch type updraft fixed bed gasifier [5]. The gasifier was a cylindrical straight up reactor consisting of airstream box and gasifier bed. The feedstock bed was supported by a bed of ceramic balls placed on perforated disk within the reactor. The gasification method became more rapidly with raise in temperature of feed gas $\left(650\right.$ to $\left.830^{\circ} \mathrm{C}\right)$. The higher feed gas temperature led to increase in concentration of $\mathrm{CO}$ (20.1 to $26.8 \%$ ) and $\mathrm{H}_{2}$ (6.6 to $12.7 \%$ ) in producer gas. The critical feed gas temperature (at which the yield of gaseous products was at the maximum) was between the ignition temperature of biomass and the melting temperature of the ash in the biomass. The updraft gasifier was normally used for gasification of conservative biomass fuel like wood, wood chips, bark, etc. There are many researches deal with the updraft gasifier as follows; Rao, et al., (2004) studied the gasification of unconventional fuels like low-density refuse derived fuel (RDF) pellets in an updraft gasifier with an inclined grate [6]. The grate inclination helped in crushing of large clinkers. An air partitioned in the gasifier ensured uniform distribution of air in the combustion zone. Higher heating value (HHV) and energy content of producer gas was $5.58 \mathrm{MJ} / \mathrm{Nm}^{3}$ and $12.2 \mathrm{MJ} / \mathrm{kg}$, respectively. The tar content from RDF pellets was $45 \%$ less than that in gas generated from wood chips. The particular gasification speed of RDF pellets was within the range reported for updraft gasifiers with fixed grate i.e. SGR 100-200 kg m-2 h-1. The cold gas efficiency obtained with RDF was $73 \%$, which was over $8 \%$ higher than that obtained with wood chips. Na, et al., (2003) gasified flammable dissipate pellets in an updraft fixed bed gasifier creased with alumina noncompliant using $\mathrm{O}_{2}$ as the gasifying medium [7]. The composition of $\mathrm{H}_{2}$ and $\mathrm{CO}$ in the producer gas was in the range $30-40 \%$ and $15-30 \%$ respectively depending on oxygen/waste ratio. At the bed height was increased the $\mathrm{H}_{2}$ and $\mathrm{CO}$ content in producer gas increased whereas $\mathrm{CO}_{2}$ content reduced. Gasification was difficult above a bed height of $700 \mathrm{~mm}$ because of the pressure drop of $\mathrm{O}_{2}$. The cold gas effectiveness was approximately $61 \%$ in the heating value of producer gas was 11.72-13.40 $\mathrm{MJ} / \mathrm{Nm}^{3}$, which was more than the heating value of producer gas generated by air gasification and the $\mathrm{O}_{2} /$ waste ratio of 0.4-0.5. The gas was cleaned of the particulate matter by a cyclone. $\mathrm{O}_{2}$ gasification was reported to generate an intermediate heating value (MHV) gas $\left(10-18 \mathrm{MJ} / \mathrm{Nm}^{3}\right)$, which is appropriate for limited pipeline distribution and as synthesis gas for conversion to methane and methanol. The purpose of this research was to study the syngas production from Golden shower tree biomass in Klong Luang District, Pathum Thani Province for producing engine shaft power and the electricity. Charcoal wood chips converted to producer gas from the updraft gasifier stove and distributed to the gasoline engine. An experimental study was carried out on July 25-26, 2017 by using an updraft gasifier, modified 4-stroke petrol engine 13 horsepower. Finally, information on the typical performance of the gasoline engine fueled with syngas is presented.

\section{Experimental setup}

The experimental was step by step set up, first of all in the 13-HP gasoline engine for multipurpose used was selected to be modified for the test. The carburetor was drilled and a copper pipe gas tube for conveying producer gas to the mixing chamber was attached. The measuring equipment such as volume air flow, thermocouples, and gas flow measuring equipment were setup and recording data as shown in Figure 1-5. The power output from an engine operating on syngas was determined by the same factors as for engines operating on liquid fuels, namely: the efficiency with which the engine changes the thermal of the flammable mixture into mechanical energy (shaft power); - the number of combustion strokes in a given time (number of revolutions per minute: rpm).

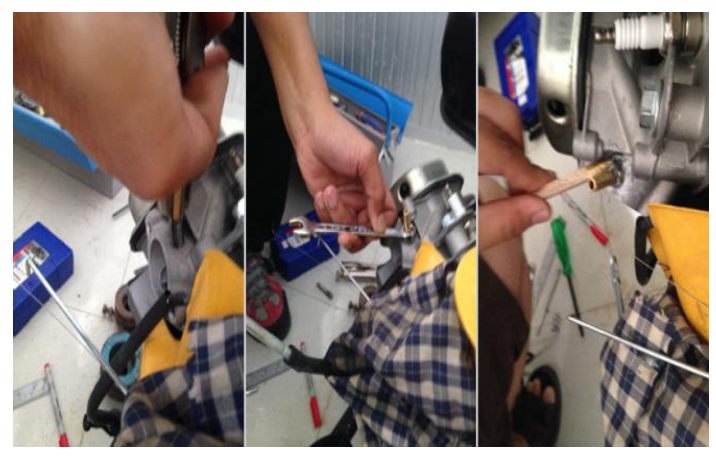

Figure 1. The carburetor of the engine was modified for the use of producer gas-air mixture.

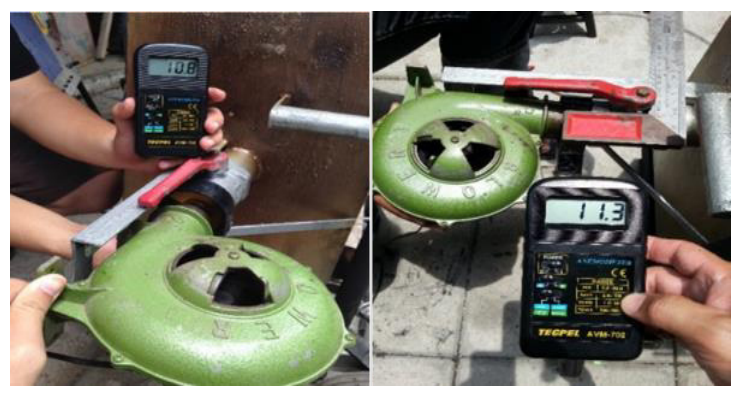

Figure 2. Air volume, mass flow measurement of the air blower gasifier stove charger.

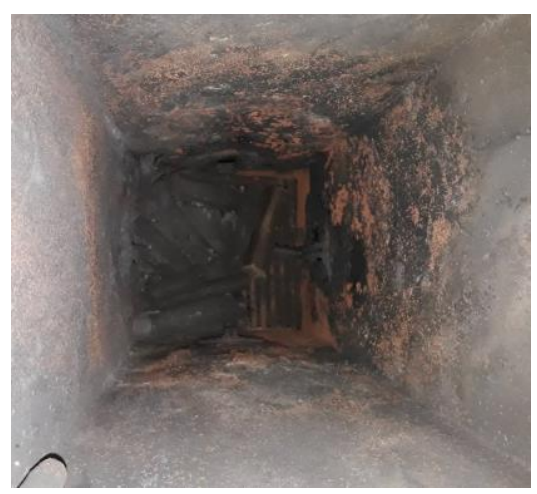

Figure 3. Combustion chamber of the the updraft gasifier. 


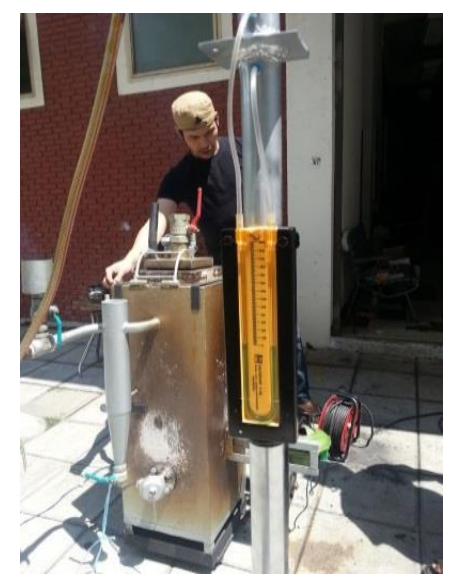

Figure 4. The updraft gasifier experimental setup.

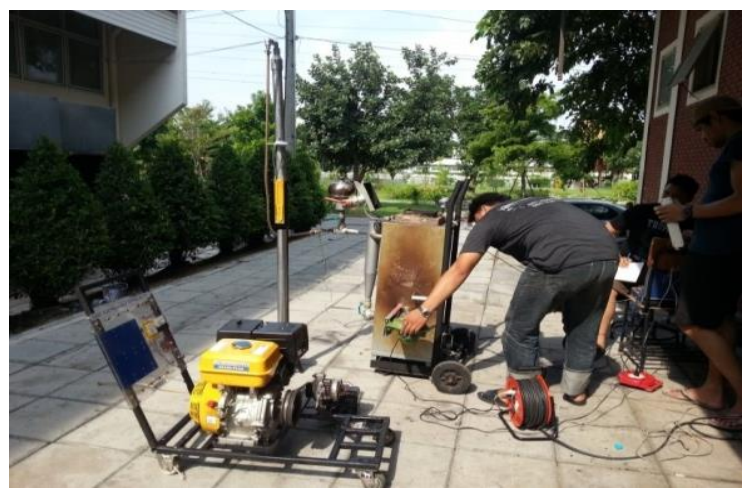

Figure 5. Syngas production and engine running test with the data acquisition.

The results of the engine performance test when the load on the engine requires the following calculation:

The engine shaft work is calculated from the equation.

$$
P=\frac{2 \pi N T}{60}
$$

$\mathrm{N}=$ Engine revolution (rps)

The generator efficiency can be calculated from

$$
\eta_{\text {gen }}=p_{\text {gen }} / p_{e}
$$

\section{Experimental results}

The experimental test of the engine running used syngas from the charcoal indicated that the average engine speed was $738.33 \mathrm{rpm}$, the average power was $12.77 \mathrm{~V}$, the average electric current was $6.9 \mathrm{~A}$, the generated power was $88.1 \mathrm{~W}$, and the engine power was $110.125 \mathrm{~W}$ as shown in Figure 6.

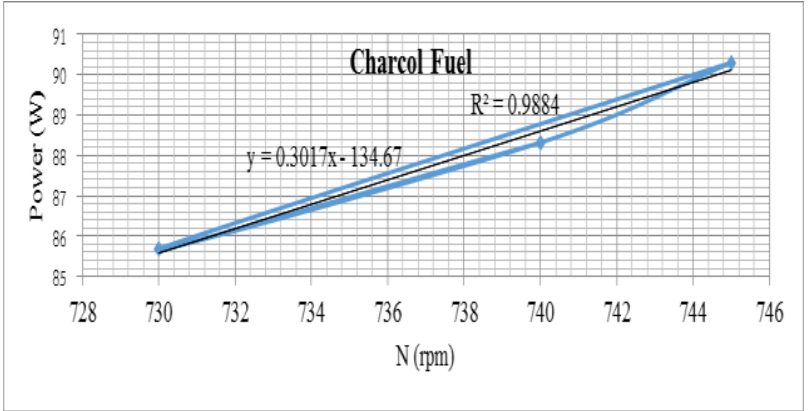

Figure 6. The relationship between the electric power and the engine speed using a charcoal fuel.

The experimental test of engine running used producer gas from the Golden Shower Tree Chips indicated that the average engine speed was $786.67 \mathrm{rpm}$, average power was $13.07 \mathrm{~V}$, average power was $7.07 \mathrm{~A}$, the generated power was $92.34 \mathrm{~W}$, and the engine power was $115.425 \mathrm{~W}$ as shown in Figure 7.

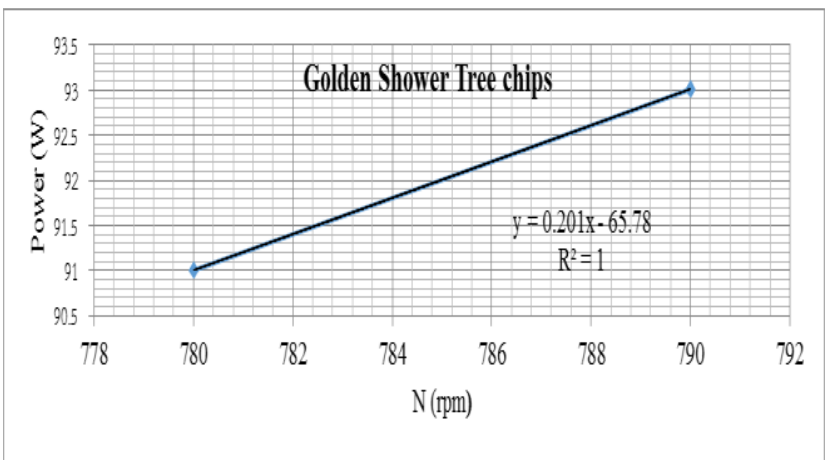

Figure 7. The relationship between electric power and the engine speed using a Golden Shower Tree chip.

The experimental test of engine running used the gasohol 91 indicated that the average engine speed was $813.33 \mathrm{rpm}$, the average power was $13.57 \mathrm{~V}$, the average power was $7.55 \mathrm{~A}$, the generated power was $102.43 \mathrm{~W}$, and the engine power was $128.038 \mathrm{~W}$ as shown in Figure 8 .

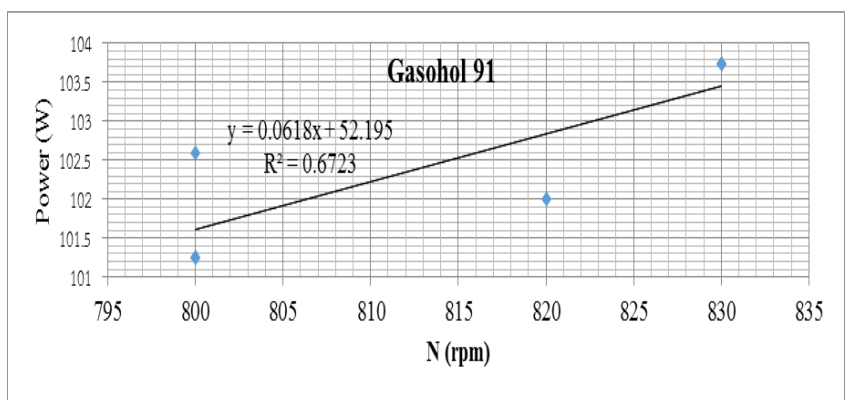

Figure 8. The relationship between the electric power and the engine speed using gasohol 91 fuel. 
According to the data obtained from this study, the use of gasoline, 91 as fuel provided more engine speed. The produced electricity was higher than the use of golden shower tree wood and charcoal as fuel. Coal combustion produces less smoke than the use of golden shower tree wood. However, golden shower tree wood gives higher heat than charcoal found in higher combustion temperatures. The golden shower tree wood and charcoal can be used for small gasoline engine

\section{Summary}

The generated power production depends on the engine revolution. For gasoline engine the increased power is less than linear because of fluctuations in the varied efficiency factors. The extreme speed of the engines fueled by producer gas is imperfect by the combustion velocity of the combustible mixture of syngas and air. Since this speed is little as paralleled to combustible mixtures of petrol and air, the efficiency of the engine can descent affectedly if the combustion speed of the mixture and the average speed of the piston become of the same order of magnitude. In the types of engines that are presently ready-to-wear, one can expect this occurrence to occur at engine speeds of about $2500 \mathrm{rpm}$. Engines fueled by producer gas should therefore generally be operated below this speed. During the test, the heat loss was very high because there has been always a fire at the top of the fuel compartment. The use of gasohol 91 fuel the engine speed, and the produced electricity were much higher than the use of wood and charcoal as fuel. The burning of coal produces less smoke than the use of Golden shower wood chips. The Golden shower, wood chip has higher heating power than charcoal, but produces more tar. The golden shower tree wood chips can be used as fuel for small gasoline engines, but should be equipped with a gas filter to avoid engine wear.

\section{References}

1. Carlos, L: High temperature air/steam gasification of biomass in an updraft fixed batch type gasifier. Ph.D. Thesis. Royal Institute of Technology, Energy Furnace and Technology, Stockholm, Sweden. (2005)

2. Reed, T. B. and A. Das: Handbook of biomass downdraft gasifier engine systems. Colorado: Solar Energy Research Institute. (1988)

3. VTT: Review of Finnish biomass gasification technologies. OPET Report No. 4. Technical research Centre of Finland, Finland. (2002)

4. Stassen, H. E. M. and H. A. M. Knoef: Small-scale gasification systems. The Netherlands: Biomass Technology Group, University of Twente. (1993)

5. Yang W., A. Ponzio, C. Lucas and W. Blasiak: Performance analysis of a fixed-bed biomass gasifier using high-temperature air. Fuel Processing Technology 87 (2006)

6. Rao, M. S., S. P. Singha, M. S. Sodhaa, A. K. Dubey and M. Shyam: Stoichiometric, mass, energy and exergy balance analysis of countercurrent fixedbed gasification of post-consumer residues. J. Biomass and Bioener. 27 (2004)

7. Na, J. I., S. J. Park, Y. K. Kim, J. G. Lee and J. H. Kim: Characteristics of oxygen-blown gasification for combustible waste in a fixed-bed gasifier. Applied Ener 75 (2003) 